\title{
Correlates of 'morningness' and breakfast frequency in a national UK sample
}

\author{
J. Huber ${ }^{1}$, S. Reeves ${ }^{2}$, Y. McMeel ${ }^{2}$ and L. Halsey ${ }^{2}$ \\ ${ }^{1}$ University of Northampton, Park Campus, Boughton Green Road, Northampton, NN2 7AL and ${ }^{2}$ Health Sciences Research \\ Centre, University of Roehampton, London, SW15 4JD, UK
}

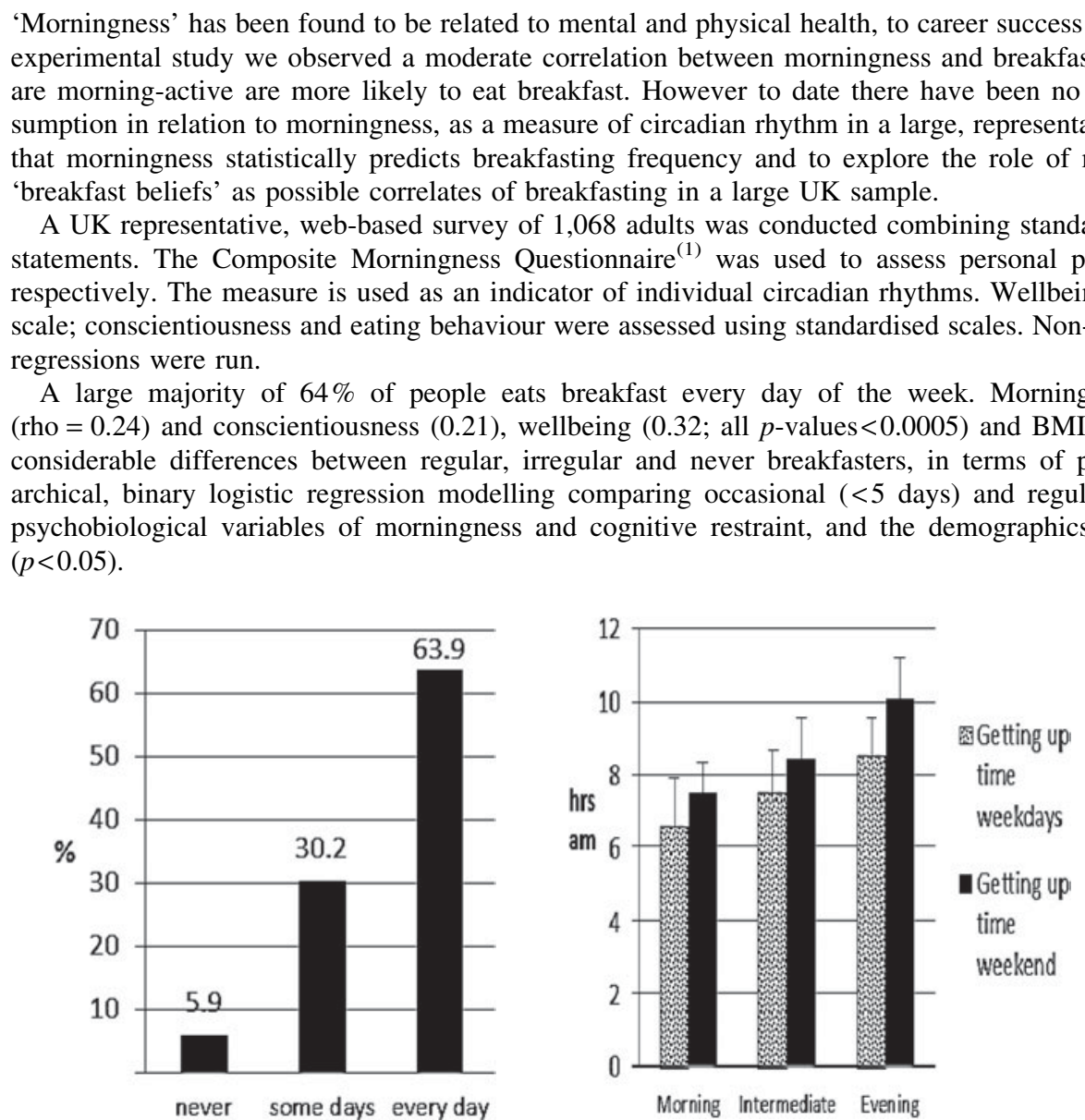

Figure 1: Breakfast eating frequency ( $\%$ of sample).
Figure 2: Time of day preference and getting up times weekday and weekend (mean hours am $+1 \mathrm{SD}$ ).

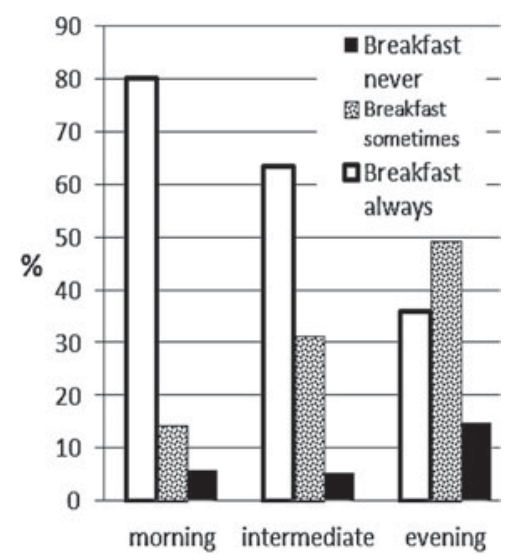

Figure 3: Time of day preference and breakfast frequency ( $\%$ of group).

Morning-active individuals and those who report higher levels of cognitive restraint are more likely to eat breakfast. In addition, older and better educated people are more likely to eat breakfast. In conclusion, morningness as an indicator of psychological preferences and partly reflecting endogenous biological clocks should not be ignored in breakfast behaviour research and health campaigns.

This work was supported by Kellogg's.

1. Barton J, Costa G, Smith L et al. (1995) Work \& Stress 9, 4-30. 